\title{
Integration of STI and HIV/AIDS with MCH-FP Services: A case study of the Nakuru Municipal Council's project on strengthening STD/AIDS control
}

James Kariba Wabaru

Bedan Kiare Kariuki

Baker Ndugga Maggwa

Population Council

Follow this and additional works at: https://knowledgecommons.popcouncil.org/departments_sbsr-rh

Part of the International Public Health Commons, Maternal and Child Health Commons, and the Women's Health Commons

How does access to this work benefit you? Let us know!

\section{Recommended Citation}

Wabaru, James Kariba, Bedan Kiare Kariuki, and Baker Ndugga Maggwa. 1997. "Integration of STI and HIV/AIDS with MCH-FP Services: A case study of the Nakuru Municipal Council's project on strengthening STD/AIDS control," Africa OR/TA Project II. Nairobi: Population Council. 
April 1997

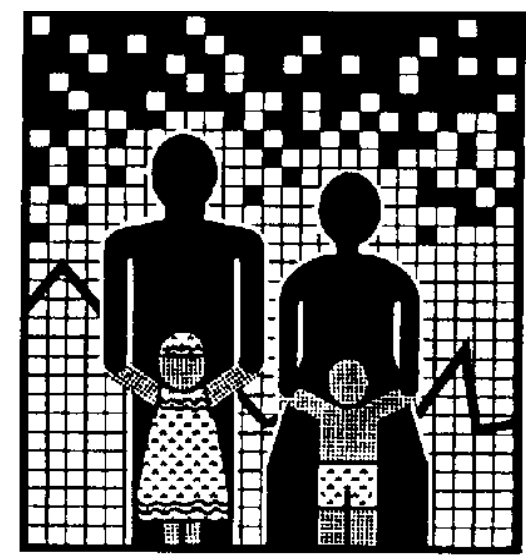

OPERATIONS

RESEARCH

TECHNICAL ASSISTANCE

AFRICA PROJECT II

THE POPULATION COUNCIL

\section{Integration of STI and HIV/AIDS}

with MCH-FP Services:

A Case Study of the Nakuru Municipal

Council's Project on Strengthening STD/AIDS

Control

Nakuru Municipal Council

James Wabaru Kariba

Bedan Kiarie Kariuki

The Population Council

Baker Ndugga Maggwa 


\section{The Population Council}

The Population Council seeks to help improve the well-being and reproductive health of current and future generations around the world and to help achieve a humane, equitable, and sustainable balance between people and resources. The Council analyzes population issues and trends; conducts biomedical research to develop new contraceptives; works with public and private agencies to improve the quality and outreach of family planning and reproductive health services; helps governments to influence demographic behavior; communicates the results of research in the population field to appropriate audiences; and helps build research capacities in developing countries. The Council, a nonprofit, non-governmental research organization established in 1952, has a multinational Board of Trustees; its New York headquarters supports a global network of regional and country offices.

\section{Africa OR/TA Project II}

The overall objective of the Africa OR/TA Project II is to broaden understanding of how to improve family planning services in Sub-Saharan Africa, and to apply operations research and technical assistance to improve services by:

- $\quad$ increasing access to a full range of family planning services and methods;

- developing service delivery strategies that are client-oriented and acceptable to various population groups;

- $\quad$ improving the operations of programs to make them more efficient and financially sustainable;

- $\quad$ improving the quality of services;

- $\quad$ strengthening the capabilities of family planning program managers to use operations research to diagnose and solve service delivery problems. 


\section{Acknowledgements}

This study was undertaken with substantial inputs from many people whose assistance is gratefully acknowledged. At the Nakuru Municipal Council, special thanks go to the Medical Officer of Health, the clinic staff and the clients for having agreed to participate in the study and for the support they gave to the study team. The Department of Community Health at the University of Nairobi, through financial support from the Canadian International Development Agency (CIDA) and the Government of Kenya, has consistently supported the participation of the Nakuru Municipal Council in the 'Strengthening of STDIAIDS Control Project in Kenya" by providing high quality technical assistance for all aspects of the integration process. Special mention must be made of Dr. Steve Moses and Dr. Elizabeth Ngugi in the Department of Community Health at the University of Nairobi who are the Officers directly responsible for technical assistance to the Project.

The Population Council is a co-operating partner in a regional initiative to address UP/STI service integration. This initiative is co-ordinated by the USAID Regional Economic Development Services Office for East and Southern Africa (RLDSO/LSA) with funding from USAID's Africa Bureau. Several members of this team have also contributed to the development arid implementation of this case study: Richard Sturgis, Sophia Ladha and Vicky Wells; at REDSO, Nairobi. and Lenni Kangas at the USAID Africa Bureau, Washington. 


\section{ACRONYMS}

$\begin{array}{ll}\text { AIDS } & \text { Acquired Immune Deficiency Syndrome } \\ \text { AIDSCAP } & \text { AIDS Control and Prevention Project } \\ \text { ANC } & \text { Antenatal Care } \\ \text { BCG } & \text { Bacilli Calmette Guerin } \\ \text { CBD } & \text { Community Based Distributor } \\ \text { CIDA } & \text { Canadian International Development Agency } \\ \text { CSW } & \text { Community Service Worker } \\ \text { CWF } & \text { Child Welfare } \\ \text { CPR } & \text { Contraceptive Prevalence Rate } \\ \text { DPT } & \text { Diphtheria Pertussis and Tetanus Vaccine } \\ \text { FP } & \text { Family Planning } \\ \text { FPIA } & \text { Family Planning International Assistance Project } \\ \text { HIV } & \text { Human Immune deficiency Virus } \\ \text { IEC } & \text { Information, Education and Communication } \\ \text { KDHS } & \text { Kenya Demographic Health Survey } \\ \text { KEPI } & \text { Kenya Expanded Program for Immunization } \\ \text { MCH } & \text { Maternal and Child Health } \\ \text { MOH } & \text { Ministry of Health } \\ \text { NACP } & \text { National AIDS Control Program } \\ \text { NCO } & \text { Non Governmental Organization } \\ \text { NMC } & \text { Nakuru Municipal Council } \\ \text { OR/TA } & \quad \text { Operations Research/Technical Assistance } \\ \text { REDSO } & \text { Regional Economic Development Services Office } \\ \text { RTI } & \text { Reproductive Tract Infection } \\ \text { RPR } & \text { Rapid Plasma Reagent } \\ \text { STI } & \text { Sexually Transmitted Infection } \\ \text { TFR } & \text { Total Fertility Rate } \\ & \text { United } \\ \text { VDRL } & \text { Venes Agency for International Development } \\ & \end{array}$




\section{Executive Summary}

Introduction: The Nakuru Municipal Council (NMC) operates five clinics and most of them are located in the residential areas with high concentrations of people. All five clinics provide basic antenatal (ANC), child welfare (CWF), STI and other curative services. Family planning services were available at four of the five NMC clinics. Besides the NMC clinics there is one Provincial referral hospital operated by the Ministry of Health (MOR) which also provides MCHFP and HIV/STI services an a special STI treatment clinic. In 1995, 27\% of women receiving antenatal care at the HIV sentinel surveillance clinics within Nakuru Municipality tested positive for HIV infection compared to $22 \%$ in 1993 and $10 \%$ in 1990.

The seven public health facilities in Nakuru Municipality are participating in a collaborative project with the Department of Community Health at the University of Nairobi, the University of Manitoba in Canada and the Nairobi Municipal City Council. The project has been jointly funded by CIDA and the Kenya Government since 1989. The long-term goal of the project is to reduce the incidence of STD's, including HIVIAIDS in Kenya. The project hopes to achieve this objective through strengthening the management of STD's and AIDS at the health facilities and by establishing sustainable community-based STD/AIDS control activities with a special emphasis on women's participation.

Model for providing STI/HIV services: It is expected that management of STD's in these clinics will be provided to clients at their first point of contact with the health system. In practical terms, this means that STD/AIDS services should be provided using an integrated approach. The model adopted by the project to facilitate the provision of STD services to clients at the first point of contact with he health system included:

- STI and HIV/AIDS/ ECI counselling for all clients receiving MCHIFP services from the clinic

- STI and HIV/AIDS risk assessment for all clients receiving MCH/FP services from the clinic

- Syndromic diagnosis and treatment of STIs

- Referral for HIV testing, counselling and management of complicated STIs.

- Prevention of cross infections in the health facilities

- Contact tracing for clients treated for STIs

- Screening antenatal clients for syphilis

Project inputs: The following activities were undertaken:

- Training of service providers in syndromic diagnosis and treatment of STIs

- Acquisition of IEC materials, posters, flow charts for the syndromic diagnosis and management of STD's, manuals and management protocols 
- Strengthening of laboratory facilities available to the MYIC clinics

Case study methodology: The methodology used to carry out the case study following:

- Review of available data and reports

- In-depth interview with program managers

- Observation of client/service provider interactions

- Exit interviews for clients receiving MCH, FP and STI services

- Interviews with service providers

- Preparation of an inventory of physical facilities, equipment, supplies and drugs at the health facilities

Using the modified Situation Analysis data collection instruments an inventory was prepared for each of the each of the five NMC clinics, the MCH-FP unit at the Provincial hospital and the special STI treatment clinic. Observations and exit interviews were conducted for 72 female clients at the seven clinics (Twenty-eight came to the clinic for ANC, 26 for family planning 12 for STIs and six for CWC services). Twenty-three of the 41 professional staff who provide $\mathrm{MCH}-\mathrm{FP}$ and/or STI services at the seven health facilities were interviewed

Key findings: The NMC clinics have an adequate basic infrastructure to provide MCH-FP and STI/HIV/AlDS services using an integrated approach. however, the clinics lack some of the basic equipment and supplies to support the integration of these services The facilities also lack basic IEC materials on STD's, HIV/AIDS and MCH-FP to be used at the facilities and for clients to carry home for future reference.

All clinic staff have attended refresher courses in the syndromic approach for diagnosing and treating STIs and basic counselling techniques for HIV/AIDS. Although most of the staff said that the training is adequate this study found that their skills in risk assessment. History taking and clinical assessment of clients receiving family planning, antenatal and STD services needed to be improved and strengthened. The possible explanations for the inadequate assessment of clients include:

- The refresher training in STD's and HIVIAIDS management did not include risk assessment, screening and counseling for many of the service providers.

- Lack of appropriate checklists or guidelines to refer to when undertaking these procedures. For example, the algorithms that staff were using to diagnose and decide on treatment for STD's at the time did not require them to carry out risk assessment and clinical examination for all clients.

- Lack of adequate equipment and supplies, e.g., specula, gloves and antiseptic lotions limited the extent to which clinical procedures could be undertaken.

- The service providers have to cater for large client loads thus limiting the time available for the detailed procedures required in STI management.

Based on these findings it is possible to conclude that training staff alone without addressing other issues may have little impact on the quality of services provided. 
Although all nurses providing MCH-FP and STD services had been trained in the use of the syndromic approach, they were still referring clients to the clinical officer and/or doctor for prescription after making a diagnosis. This was because in Kenya, the Poisons Act, which identities what medications can be prescribed by the various cadres of health staff, prevents nurses from prescribing antibiotics. Training nurses in the syndromic approach and expecting them to provide an integrated service without reviewing this Act will not change the way services are provided.

The CIDA funding is only used to facilitate the acquisition of drugs for the Nakuru Municipal Council clinics. Thus all the five NMC clinics had adequate supplies of the drugs recommended by the National STD Control program for managing STD's but the General Hospital and special STD clinic did not have these drugs and were referring clients to the pharmacies to purchase the drugs Moreover at the time of the study the NMC clinics were experiencing severe shortages of drugs for treating non-STD ailments. The provision of drugs that are specifically earmarked the use in STI treatment without providing for other ailments was undermining the very principles of integration that the staff were being asked and trained to adopt.

The program was reaching many clients with STD services and many antenatal clients were getting tested for syphilis infection. However, contact tracing was a major problem with fewer than one-third of the clients treated for STD's having their contacts traced through the project initiatives. Staff were not informing most of the clients treated STD's about the importance of contact tracing and partner notification.

Knowledge about STD's and HIV/AIDS was poor among clients receiving MCH-FP and STD services at the project clinics. This was not surprising since staff rarely discussed STD's and HIV/AIDS with clients in the consultations observed. These findings represent major missed opportunities to inform clients about STD's and HIV/AIDS.

The study has shown that adding STD and HIV/AIDS services to an already existing program is no easy task. However, the NMC should be commended for the great effort it has put into the project and the successes it has achieved so far. Although there are many areas that need to be addressed, through the project STD and HIV/AIDS services have become more easily accessible to clients through the project initiatives and many clients are being treated at their primary points of contact with the health care systems. 


\section{Background}

\section{Introduction}

Most national MCH-FP programs and donors in sub-Saharan Africa are considering shifting their programmatic strategies toward a broader reproductive health service approach, which would include integrating STI and HIV/AIDS services into the existing MCH-FP programs. This shift is based on the belief that integration of these services will lead to more cost-effective and better quality services. There is an assumption, however, that the basic infrastructure that exists for the MCH-FP programs can absorb the extra demands of the STI/HIV/AIDS services with minimal additional inputs. There is also the assumption that staff providing $\mathrm{MCH}-\mathrm{FP}$ services require only minimal training to be able to provide STI/HIV/AIDS services. Both MCH-FP and STI/HIV/AIDS services target very similar populations (i.e., the sexually active), and therefore integrating them could maximize use of existing resources. There is a further assumption that clients receiving MCH-FP services already find these services acceptable, therefore, the addition of STI/HIV/AIDS services would reduce the stigma associated with STIs and HIV/AIDS services when provided in isolation.

To date efforts to integrate services have been mostly pioneer projects that have not been adequately documented and shared with other interested parties. To address the need to learn from the many experiences of integration that currently exist in the region, a consortium of service and research agencies has been established with USAID funding. The consortium includes: USAID Africa Bureau, USAID/REDSO for East and Southern Africa, The Population Council, Pathfinder International, Data for Decision-Making project at Harvard University, and the Commonwealth Regional Secretariat for East and Southern Africa. This consortium is undertaking a series of activities to study the feasibility of integrating STI and HIV/AIDS services with existing MCH-FP services in the region. As its contribution to this effort, The Population Council, through the Africa OR/TA Project II, is carrying out a number of case studies of projects and programs that have initiated integrated services with MCH-FP services.

This report describes a case study of the integration activities being undertaken by the Nakuru Municipal Council (NMC) in collaboration with the Department of Community health at the University of Nairobi with financial support from CIDA in Nakuru district, Kenya. The case study was carried out by The Population Council in collaboration with the Nakuru Municipal Council and the Department of Community Health, University of Nairobi.

\section{Nakuru Municipality}

Nakuru Municipality is 160 kilometers to the north-west of Nairobi on the TransAfrica highway and Kenya/Uganda railway which links the Mombassa sea port with several East and Central African countries. The municipality is in Nakuru District within the Rift Valley Province and serves as the administration and commercial headquarters for the district and province. Nakuru municipality covers a total area of 290 sq. kilometers.

According to the 1989 census, the municipality had a population of 163,927 people. However, in 1995 , the population was estimated at 221,278 people representing a $5.7 \%$ annual growth rate.

Based on the estimates for 1995, there are approximately 56,000 women aged 15-49 years living in the municipality'. This represents $20 \%$ of women in reproductive age-group in Nakuru District. 
The most recent Kenya Demographic and Health Survey (KDHS) ${ }^{2}$ found the contraceptive prevalence rate to be $22 \%$ and $23 \%$ for modern contraceptive methods in the Rift Valley province and Nakuru District, respectively. This was lower than that for the whole country (32.7\%). During the same survey, it was found that $36.5 \%$ of women in Rift Valley Province had an unmet need for contraceptive services. Most of the unmet need was for spacing rather than limiting. It is not possible to dis-aggregate the KDHS data to find these measurements for Nakuru Municipality.

The Nakuru Municipal Council (NMC) has a Department of Health headed by a Medical Officer. The Department is responsible for ensuring that residents have access to health services and that the basic public health requirements are followed by all persons living within the municipality.

The NMC operates five clinics and most of them are located in residential areas with high concentrations of people. All five clinics provide basic antenatal (ANC), child welfare (CWF), STI and other curative services. Family planning services are available at four clinics. STI services are available at lithe MCII-FP units in the NMC clinics. Basic laboratory facilities (excluding HIV testing) are available at only one clinic. Clients requiring HIV testing and counseling are referred to the general hospital. All NMC clinics are open to the public Monday to Friday between 8.00 a.m. and 5.00 p.m.

Besides the NMC clinics there is the Provincial referral hospital operated by the Ministry of Health $(\mathrm{MOH})$ which also provides MCH-FP and STI/HIV services. In addition, there is a special STI treatment clinic within the compound of the General Hospital. This clinic is maintained and managed by a committee made up of members representing the NMC and the Provincial hospital.

1. The Nakuru Municipal Council (1995). Paper on Development, Settings, Needs and Economic Activities of the Munirin $1 i^{\text {ter }}$ Intamn 1 manonto 
2. National Council for Population and Development, Central Bureau of Statistics and Macro International Inc. (1993). Kenya Demographic and Health Survey, 1993. National Council for Population and Development, Nairobi, Kenya.

In the twelve months preceding the case study, each of the six MCH-FP units served on average, 17,817 clients $^{3}$. Figure 1 shows that most of the clients received child welfare and antenatal services. Each of the six health facilities with MCH-FP units treated on average 1,580 clients for STIs. Although some of the STI clients were treated in the MCH-FP units, the way records are kept it is difficult to determine what proportion. During the same period, the special STI treatment clinic treated 4,661 clients for STIs.

The five NMC clinics prepare monthly summaries covering the number of clients receiving STI services from their facilities by syndrome. These summaries are used by the CIDA project to determine clinic requirements (e.g., drugs, gloves, cotton wool, laboratory reagents, specimen collection supplies, etc) Using reports for the period January 1 to December 31,1995 , it was found that the five clinics reported that they had provided STI services to 7,076 clients over the 12 months. Figure 2 shows that urethral discharge was the most common symptom by pelvic inflammatory disease (PID) among the clients treated for STIs in 1995. The small difference between the number of clients reported by the NMC clinics and the average calculated for each MCH-FP unit using data from the five MCH-FP units may be due to the different periods for which these figures were obtained. Population-based data on STIs are generally lacking from Nakuru District and the municipality.

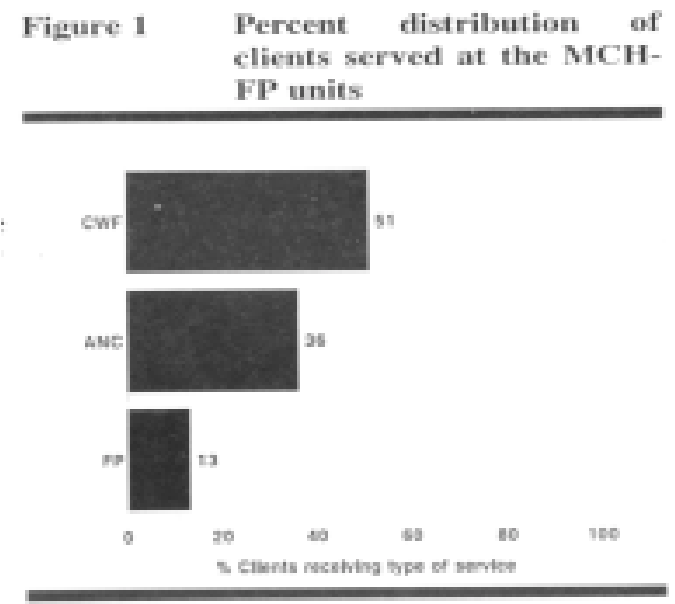

Figure 2 Distribution of syndromes of STIs treated at the five NMC clinics in 1995

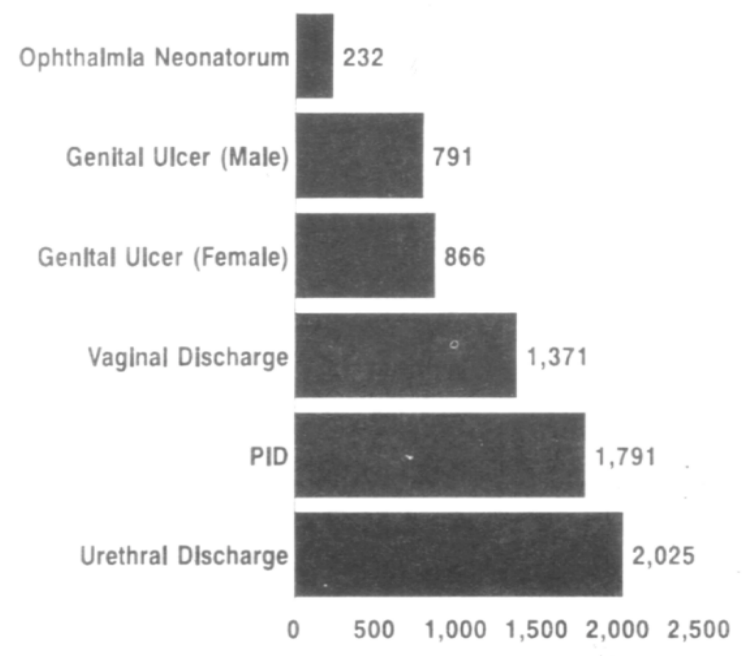


Nakuru Municipality is one of the sentinel surveillance centres established by' the National AIDS Control Program (NACP) to monitor the progress of the AIDS epidemic in Kenya ${ }^{5}$. Samples of women receiving antenatal care services at these centres, are screened for HIV infection at regular intervals. Data from the Nakuru sentinel surveillance centre shows an increase in the number of women receiving antenatal care who test positive $n$ for HIV infection. Similar trends have been observed in many other testing centres in the country (Figure 3) The data available from the National AIDS Control Program, the Nakuru Municipal

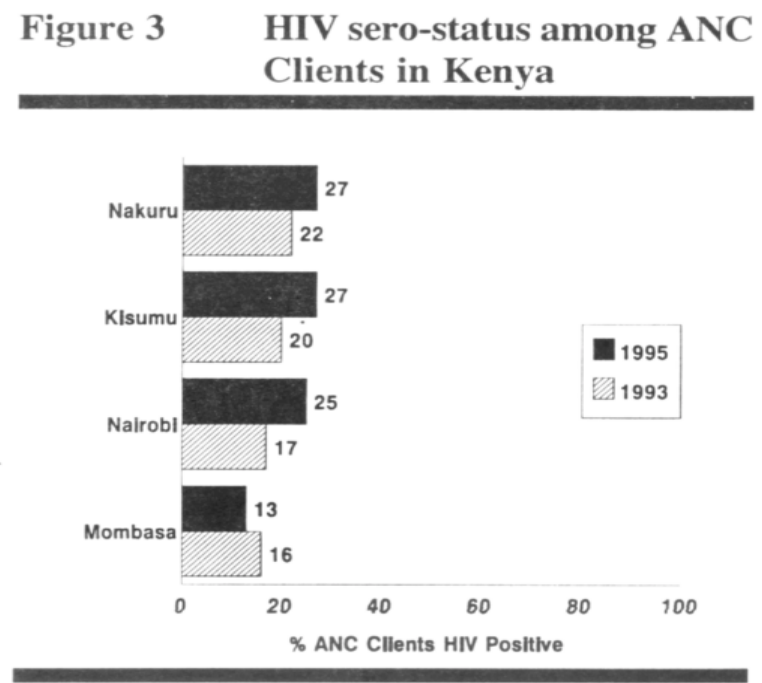

3 These data were obtained from the service statistics kept by the clinics during the case study using the inventory.

Council clinics and the MOH annual reports suggests that there is need for STI/HIV services among women receiving health services from public health facilities.

\section{Integrating STI/HIV/AIDS services with MCH-FP services}

Prior to 1988 and the start of the project, STI/HIV/AIDS services were available only the curative department at the five NMC clinics and General Hospital. Clients who came for MCH-FP services and had symptoms STIs and/or HIV/AIDS were referred to the curative department for diagnosis and treatment. At the rime the special STD treatment clinic did not exist. This meant that clients had to queue up twice or make separate visits for the MCH-FP and STI/HIV/AIDS services. The curative departments at these facilities provided only diagnosis and treatment with no IEC and counselling on STI/HIV/AIDS for the clients. The NMC did not have any community out -reach programs to provide IEC on MCH-FP and STI/HIV/AIDS services.

In early 1988, the NMC realised that STIs were on the increase in the municipality and surrounding areas. They also had observed that clients seeking STI services accounted for significant portion of all the outpatient services provided within their health facilities. On recognising this need the NMC started looking for ways of addressing it more effectively. Later in the year, the Department of Community Health at the University of Nairobi approached and requested the NMC to participate in a multi-center study on the "Strengthening of STD and AIDS Control in Kenya". This request was seen by the NMC as an opportunity to address an issue that was already high on their agenda and key agreed to participate. Thereafter, the Nairobi City Commission, Nakuru Municipal Council, the Department of Community Health at the University of Nairobi and the University Of Manitoba in Canada developed a joint project proposal submitted to CIDA and the Government of Kenya for funding. In response to this proposal, CIDA approved a 5-year bilateral funding (between October 1990 and October 1995) with the Government of Kenya to carry out a pilot project on

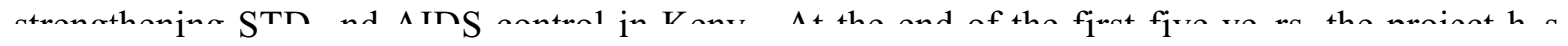


been funded for another five-year period starting 1996.

The long-term goal of the project is to reduce the incidence of STDs, including HIVIAIDS in Kenya $^{6}$. The project seeks to achieve this objective through strengthening the management of STDs and AIDS at the health facilities and by establishing sustainable community-based STD/AIDS control activities with a special emphasis on women S participation. The project covers five of Nairobi City Council clinics in addition to all the five Nakuru Municipal Council clinics, the Nakuru Provincial General hospital and the special STI treatment clinic within the Provincial hospital.

4 Department of Community Health, University of Nairobi (1996). Nakuru Monthly Summary Reports (January - December 1995). Nairobi, Kenya. (Each of the clinics prepares a monthly summary report, which they send to the project co-ordinator at the University of Nairobi. The report includes data on the different STDs treated at the clinics (these are classified by syndrome), the age and sex distribution of the clients, number of contacts traced, revisits and stocks of drugs and other supplies).

5 National AIDS Control Program, Ministry of Health and the National Council for Population and Development (1996). AIDS in Kenya: Background, Projections, Impact and Interventions. Nairobi, Kenya

Model for Providing STI/HIV services

The model adopted by the project to facilitate the provision of STD services to clients at the first point of contact with the health system included.

I. IEC and Counseling: Through the project. IEC and counseling on STIs and HIV/AIDS activities are to $\boldsymbol{b} \boldsymbol{e}$ carried out for the communities living within the municipality and all clients presenting to the health facilities. Peer educators were elected by the commercial sex workers and trained in the provision of IEC on STIs, HIV/AIDS and MCH-FP to their peers. The clinic staff are expected to provide IEC and counseling to all clients seen at the clinics. The program has a team of counselors who visit schools and the industries to provide IEC, counseling and non prescription Contraceptive methods including condoms to students and employees at their places of work.

2. Risk Assessment: Risk assessment is to be undertaken for all clients receiving MCH-FP services at the health facilities. It is expected that clinic staff will gather information from all clients that will help the staff decide clients' risk status for STIs and HIV infection. All clients should be asked about number of sex partners, history of STD's, marital status, condom use, partner's sexual behaviour, occupation and residence.

3. Diagnosis and Treatment: The clinic staff are expected to use the syndromic approach to diagnose and treat common STIs among clients seen at the health facilities. The staff rely on the available algorithms to decide the treatments for various STI syndromes. The algorithms were developed by the project in collaboration with the STD Control Unit of the Ministry of Health. Although these algorithms have been validated in specialised STD treatment clinics no similar efforts had been undertaken to validate them in the MCH-FP clinics.

The NMC has established a laboratory at one of the five NMC clinics. The other clinics send

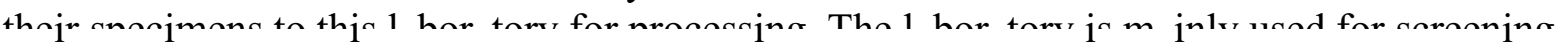


antenatal clients for syphilis, and testing clients who are not responding to drugs prescribed using the syndromic approach. The NMC laboratory does not carry out HIV testing and the five NMC clinics rely on the Provincial hospital for this service.

4. Referral systems: The NMC clinics collaborate with the Provincial Hospital on this project. One of the principal investigators serves as a consultant on STIs and other skin diseases at the hospital to whom all complicated STI and HIV/AIDS cases are referred for review and further treatment.

5. Prevention of cross infections: The project has introduced measures to prevent the spread of infections including HIV through clinic procedures. These have involved training of clinic staff in infection prevention procedures and the introduction of improved sterilization procedures and safe waste disposal mechanisms.

4 Gangopadhyay P.T., Romanowski B., and Wilson D., (1995). Strengthening STD/AIDS Control in Kenya Project: Report on Final Evaluation, Canadian International Development Agency, East and Middle East Branch, Ottawa, Canada.

$5 \quad$ Contact Tracing: The project staff are expected to carry out contact tracing for clients with STIs and HIV/AIDS. Clients treated for STIs should be verbally requested to inform their partners and request them to come to the clinic for treatment. Written notes should be sent to the partners through the primary contact clients. Sometimes, prescriptions and/or medications for the partner should be given to the client without requesting that the partner comes to the clinic However. Identification of the contact is not a prerequisite for receiving treatment sit the health facilities.

$6 \quad$ Screening antenatal clients for syphilis: All women receiving antenatal care from the clinic facilities are expected to be screened for syphilis. Blood should be collected from all antenatal women and sent to the referral laboratory. There is no fee charged for any STI laboratory tests including syphilis testing for clients served at the NMC health facilities. 


\section{The Nakuru Municipal Council Integration Model}

1. Carry Out STD and HIV/AIDS risk assessment and screening for all clients receiving MCH-FP and other services at the health facilities;

1. Provide information, educate and counsel all clients receiving services from the health facilities about STDs and HIV/AIDS;

3. Provide information, educate and counsel hard to reach groups like commercial sex workers, men at the workplace and youth in schools using clinic staff and trained peer educators;

4. Diagnose and treat STDS using the syndromic approach and the algorithms available;

5. Establish referral mechanisms for clients requiring HIV testing and specialized STD treatment;

$6 \quad$ Prevention of cross infections within the health facilities;

7. Carry out contact tracing and treatment for STD clients;

8. Screen and treat all antenatal clients for syphilis.

The NMC and the Departments of Community Health and Medical Microbiology at University of Nairobi, in collaboration with the University of Manitoba in Canada have carried out the following act activities to facilitate the improvement of the quality of STI and HIV/AIDS services provided to clients using the project service model described above:

1. Training of service providers: All nurses' and clinical officers working in the NMC clinics were trained in using the syndromic approach to diagnose and treat STIs. The service providers were also trained in carrying out education and counselling activities for STIs/HIM/AIDS. Training materials, tow charts curricula and STD management algorithms were developed based on local and international research findings ${ }^{7}$. The training materials were developed by the project staff in collaboration with the Ministry of Health, University of Nairobi and the University of Manitoba.

2. Acquisition of IEC materials, posters, flow charts, STD manuals and management protocols: The MOH has several IEC materials developed by the

7 Wotton K.A., Ngugi E.N., Eldridge G., et al., (1994) Facilitator Notes for the Training of Health Workers in Sexually Transmitted Diseases. Department of Community Health, Universitv of Nairobi. Nairobi. Kenva. 
National STD/AIDS control program, the WHO and other agencies. The project facilitates the acquisition of these materials for all the seven public health facilities in Nakuru Municipality.

3. Provision of drugs for the treatment of common STIs: The five NMC clinics are supplied with drugs for treating clients with STIs separately. The project uses the National Guidelines and Ministry of Health algorithms on the treatment of STIs to identify and purchase the drugs. These drugs are to be used solely to treat STIs and a different record book is used to monitor the drugs. Besides the drugs, the project provides condoms, gloves, syringes and needles to the five NMC clinics. The Provincial hospital and special STI treatment clinic are supplied with drugs and/or other supplies through the project.

\section{Strengthening of laboratory facilities available to the MIC clinics: This} involved training of laboratory staff in basic techniques for STI/HIV laboratory tests including RPR for syphilis, gram stain, culture and basic microscopy procedures in the Department of Medical Microbiology at the University of Nairobi. The project also provided basic equipment and supplies required for the diagnosis of common is to the referral laboratory established a clinic. The project provides some funds to complement the locally available manpower in transporting laboratory specimens and results from and to the participating health facilities. The project has also provided also provided desktop centrifuges, RPR rotator cards and testing kits for screening antenatal women for syphilis to the laboratory.

Through the above project inputs, it was expected that management of STDs in the model clinics will be provided to clients at their first point of contact with the health system. For example, the same service provider should treat a client seeking family planning services who also has an STD at the same consultation. In practical terms, this meant that $\mathrm{MCH}$, family planning, STD and HIV/AIDS services were to be provided using an integrated approach.

\section{Study Methodology}

The population Council's Africa OR/TA project II, I collaboration with other consortium members (Pathfinder International, REDSO/ESA, Data for Decision Making Project, Centres for Disease Control and USAID Africa Bureau) developed a methodology for conducting case studies of programs and projects that have adapted and integrated approach to provide STI, HIV, AIDS and MCH-FP services. Using this methodology data were collected as follows:

Review of available data and reports: The Kenya Demographic and Health Surveys (KDHS) reports, Ministry of Health Annual Reports, Census reports, the final evaluation 
report for the first phase of the CIDA funded project and various reports and strategic plans prepared by the NMC were reviewed. The review was used to establish the characteristics of the catchment area, population, contraceptive practices and statistics of STIs, HIV and AIDS. The review was also used to trace the evolution of the NIVIC services to the time of the case study.

In-depth interview with the deputy program manager: The deputy program manager was interviewed using a semi-structured interview guide. The interview guide covered the manager's understanding of the integration process, the historical evolution of the integration process (why, how and when did the process start), the type of integration model and its components, activities carried out to facilitate the process, resource mobilization and budgeting, monitoring and evaluation activities, policy commitment, experiences to date, and future plans.

Modified Situation Analysis; The modification involved reviewing and expanding the data collection instruments to facilitate the collection of information on facility and staff preparedness to provide STDs and HIVIAIDS services in the MCH-FP setting, quality of STD services clients were receiving and clients' knowledge about these conditions. The data collection instruments were revised using the risk assessment indicators suggested by' the WHO9, the sub-Committee on STIs and HIV/AIDS of the Evaluation Project, the training manual used by the CIDA project to train NMC clinic staff1 1 and other locally available guidelines o the delivery of MCH-FP and STI services12.

Using the modified data collection instruments an inventory was prepared for each of the seven public health facilities. Observations and exit interviews were conducted for 72 female clients at seven clinics (28 came for ANC, 26 for family planning, 12 for STIs and six for CWC services). Twenty three of the 41 professional staff who provide MCH-FP services at the seven health facilities were interviewed.

9 Mertens T. Carel M., Sato P., et al, 1994. Prevention Indicators for evaluating National AIDS Control Programs. AIDS 8:1359-1369.

10 Dallabetta g. , and Hassig S. , Eds. In Indicators for Reproductive Health Program Evaluation, (1995). A final report of the Sub-committee on STD/HIV. A publication of Carolina Population Center, Chapel Hill, NC27516-3997.

11 Wotton K. A. Ngugi E. N., Eldridge G., et al. , (1994) Facilitator Notes for the Training of Health Workers in Sexually Transmitted Diseases. Department of Community Health, University of Nairobi, Nairobi, Kenya. 
Standards for Service Providers, 1991, Kenya

\section{Principal findings}

\section{Preparedness to offer integrated services}

\section{a) Clinic facilities:}

Physical Infrastructure: All seven-health facilities surveyed had the basic infrastructure necessary for the provision of good quality MCH-FP and STI/HIV/AIDS services. The health facilities are within easy reach of the populations they serve. All the facilities surveyed have mains-electricity and piped water; however, none of the seven public facilities had an alternative source of lighting for use in case of power failure. All clinics have designated waiting areas which are protected from rain, sunshine and have adequate seating to facilitate the provision of group "health" talks and display of IEC materials. There are functioning toilets for use by clients at all health facilities.

Counselling and examination rooms: The counselling and examination rooms are separate from the waiting areas at all NMC clinics and the Provincial Hospital. All facilities are capable of providing adequate auditory and visual privacy for the clients during counselling and examination. The rooms also have adequate lighting and are well kept. Adequate water and bed linen in the examination rooms were missing at four of the health facilities on the day of the study. The examination room at the special STI treatment clinic lacked visual privacy, adequate lighting linen and water.

Equipment and supplies:

Sterilising equipment, weighing-scales, Figure 4 Availability of Equipment blood pressure equipment and EPI and Supplies

refrigerators were available at all the facilities except the STI clinic. However, Figure 4 shows that more than one-third of the facilities lacked some of the basic supplies necessary for providing reports prepared by the clinics also revealed that gloves, antiseptic lotion syringes and needles are frequently missing at most of the project clinics. Vaginal specula and a source of light (torch or angle poise lamp) were available at four of the seven facilities. Waste disposal facilities are

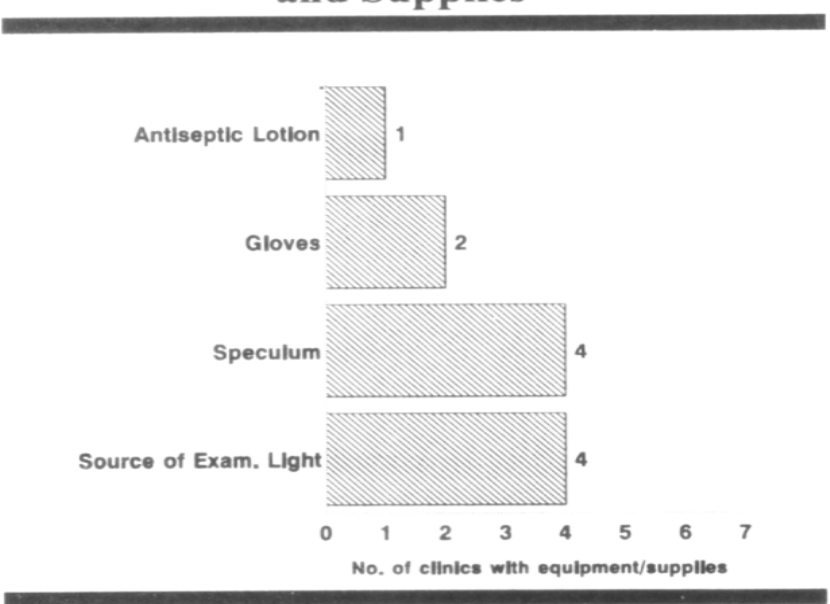
generally inadequate at all the facilities. Used disposable syringes and needle are collected in containers, which are either burnt or thrown in pit latrines. Lack of adequate equipment, supplies and proper waste disposal facilities at these facilities makes it difficult for the staff to nractice what thev learned ahout the nrevention of cross infections. 
IEC materials and Activities: Although Information, Education and Communications (1 EC) activities are a major component of any model adopted for the provision of STI/HIV services, data from this study show that facilities are not well prepared to undertake these activities. IEC materials were generally lacking at all the facilities surveyed.. For example, flip charts on family planning and child welfare were available at only one and two facilities, respectively. Brochures and/or pamphlets on HIV/AIDS were found at one facility only. Five facilities had posters on HIV/AIDS, but wall posters on family planning, STIs, child welfare were available at only three of the facilities. None of the posters had combined messages on the two themes (STD/HIV and MCH-FP) and all were in English. Although the clinic staff is expected to organize group "health talks" for clients receiving MCLIFP services from the facilities on each clinic day, these were observed at only two health facilities during the study. The two group "health talks" observed did not include STIs and HIV/AIDS.

\section{b) Accessibility}

Opening times and time spent by clients: All the health facilities are expected to start providing services at $8.00 \mathrm{a} . \mathrm{m}$. and close at 5.00 p.m. daily from Monday to Friday. Data from this study shows that the clinics start providing services to clients on average at 9.00 a.m. However, the majority ( $88 \%$ and $96 \%$ ) of clients receiving $\mathrm{MCH}$ and FP services, respectively, from these facilities said that the times when the facilities are open were convenient for them.

Clients receiving FP and $\mathrm{MCH}$ services were asked to estimate the time spent at the health facilities to receive services. The majority said that they had stayed on average for one hour and 40 minutes from the time they arrived at the facility to the time when they finished receiving services. A significant number (23\%) of the FP clients felt that the time spent at the facility was too long. Although the clients receiving only $\mathrm{MCH}$ services stayed for the same time as those receiving FP services, a much higher proportion (62\%) felt that the time they spent at the facility was too long. The 12 clients who received STI services stayed for one hour and twenty minutes on average at the clinic and five (42\%) of them felt that this time was too long. The interaction between the clients and the service providers lasted between 18 and 24 minutes (18 minutes for family planning, 19 for STI and 24 for Antenatal clients). If the estimate of the time spent at the clinics by the clients is accurate, the time spent by clients waiting for services is much more than that spent on the actual consultation.

Most of the clients interviewed (77\% and $65 \%$ of the clients receiving FP and $\mathrm{MCH}$ services, respectively) had walked to the health facility. For the MCH and FP clients who walked to the clinics, the majority estimated that they took on average 21 and 28 minutes, respectively, to get to the health facility. Generally, clients who received STI services said that they took longer to get to the health facilities. For example, the five clients who received STI services and walked to the health facility said that they took more than 60 minutes to get to the clinics. Although the numbers are small, these data suggest that clients receiving $\mathrm{MCH}$ and FP services live within easy reach of the facilities that they use for these services compared to those receiving STI services. Half of the clients 
receiving STI services and more than one-third of the clients receiving family planning services said that they had health facilities closer to their residences than the one they had visited for these services compared with less than one-third of the MCH-FP clients. Availability, quality and cost of services at the facilities were major factors considered by the clients when choosing a facility to go to for services. Another common reason was that the clients had other businesses to take care of within the vicinity of the facilities they visited. Only one client who visited an alternative clinic for family planning services gave privacy and confidentiality as the reasons. None of those seeking STI and MCH services gave privacy as a reason for not getting these services from a clinic nearer to their homes than the one they visited.

Availability of Services: All the seven facilities surveyed were providing STI services on the day of the survey. Antenatal care, child welfare and postnatal care were available at six clinics while family planning services were being provided at five of the facilities. Staff at the special STD clinic said that they usually do not provide MCH-FP services but refer all clients needing these services to the Provincial Hospital. HIV/AIDS testing was available at only one of the facilities visited during the study period. Although all the facilities were providing STI services on the day of the survey, only four of the 60 clients who received only $\mathrm{MCH}$ and UP services from these facilities were aware that STI services were also available at these facilities. One-half of the 46 clients who received only MCH and STI services were aware tat family planning services were available at the facility. These data show that although the services are available at most of the clinics, few clients are aware. (Clients can be made aware of the availability of services through billboards/signs and/or through other IEC activities at the clinic and in the community. At the time of the study there were no visible signs/billboards or adequate IEC materials and activities through which the clients would have been informed about the availability of all of these services at the NMC clinics.

\section{c) Staff Preparedness}

Training: Most of the staff interviewed had completed their basic training' 16 years prior to to this case study. The basic training covered family planning, STI and HIV/AIDS services for seven, four and one service providers respectively. Figure 5 shows that for most of the service providers, training in family planning, STI and HIV/AIDS has been through in-service courses(post basic and refresher). For example, 19 service providers have attended a post basic and/or a refresher course in family planning while 21 of them had attended a post basic/refresher course that included topics on STI and HIV/AIDS services.

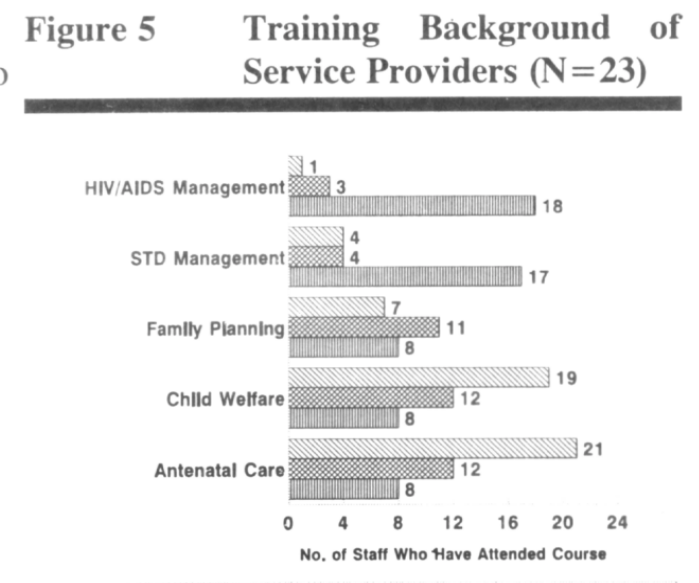

$\mathbb{N}$ Baslc Course Post Basic Course $\square$ Refresher Course 
Most of the service providers who have been trained in STI and HIV/AIDS services have been trained in the past three years as part of the ongoing project. More than half the staff who said that they had attended a course on STI/HIV/AIDS were trained in counseling and the use of the syndromic approach for diagnosis and treatment of STIs. A significant number (9) had not been trained in STI risk assessment procedures (Figure $6)$.

The sensitivity and specificity of the syndromic approach have been reported to be low when the approach is used in populations at low risk for STIs' ${ }^{4}$. However, the sensitivity and specificity are greatly improved if a risk assessment score is added to it. Since MCH-FP clients are generally

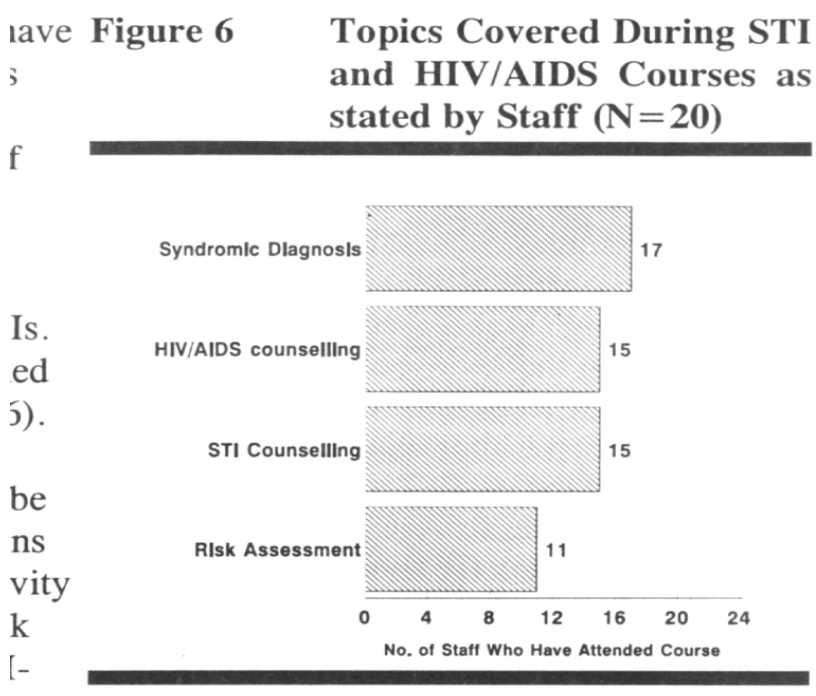
low risk populations, training staff providing STI and HIV/AIDS services in risk assessment procedures may improve the quality of services provided.

\section{Experiences with the integrated STD/AIDS service model}

\section{a) Assessing clients for STDs and HIVIAIDS}

Risk assessment: To assess the competency of the staff in carrying out risk assessment for STIs and HIV/AIDS, they were asked to list the questions they would ask to find out the clients' risk status for these infections. Most the service providers said that they would ask clients about the number of sex partners they have had in the past one year, occupation and residence of the regular sex partner. Although history of STI and/or HIV/AIDS in the client and partner are listed as indicators of the risk status of an individual for these infections, less than half the staff said that they would ask their clients

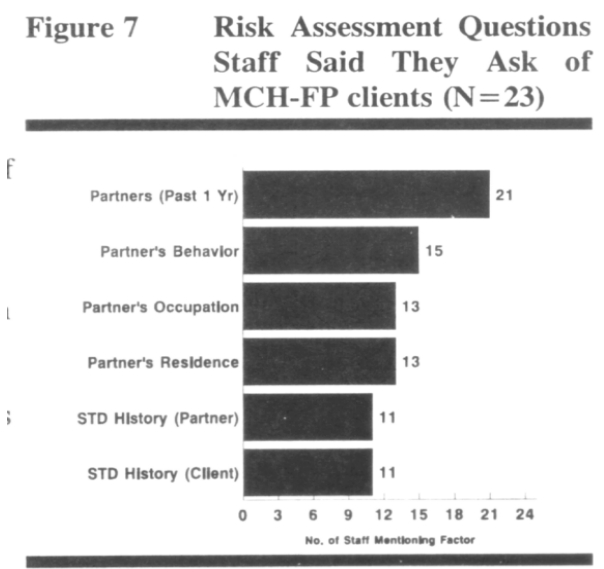
about these risk factors (Figure 7). 
14. Costello C.D., Maggwa A.B.N., Mati J.K., et al., (1994). Risk Factor for Gonorrhoea, Syphilis and Trichomonas Infections Among Women Attending Family Planning Clinics in Nairobi, Kenya. Genitourin. Med. 1994, 70:155-161.

Data from the observations of providerclient interactions confirm that clients receiving VICH-UP and STI services from the NMC clinics are hardly asked any questions that would provide the information that is essential for risk assessment. For example less than one-quarter of the clients observed while receiving antenatal and family planning services during the study period were asked about history of STDs in themselves and their partners concerns about STIs and (1 number of sex partners in the past 12 months during the interaction with the service providers. women attending the clinics for antenatal care were less likely than family planning clients to be asked questions that would help to decide their risk status for STD and HIV/AIDS.

History Taking: Service providers were asked to $t$ the questions they would ask a client who presented they would ask a client who presented with a vaginal discharge that would assist in determining the possible cause for the discharge. Figure 9 shows that less than one-half of the staff interviewed said that they would ask about presence of symptoms in the partner, residence of clients I the past three months and marital status. However, more than two-thirds of the staff said they would ask clients about the characteristics of the discharge. These findings suggest that staff focus primarily on describing the discharge for purposes of fitting it into one of the syndromes and neglect to identify factors that might help them decide the cause of the discharge. This is not surprising given that the flow charts used by the staff address identifying the treatment category that the discharge fits in rather than

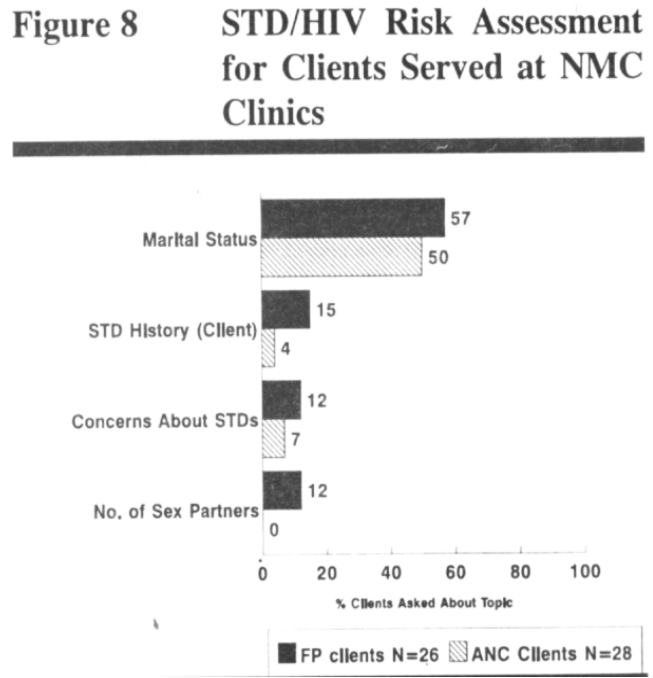

Figure 9: $\quad$ Topics Staff Said They identifying possibleskadients. With Vaginal Discharge $(\mathbf{N}=\mathbf{2 3})$

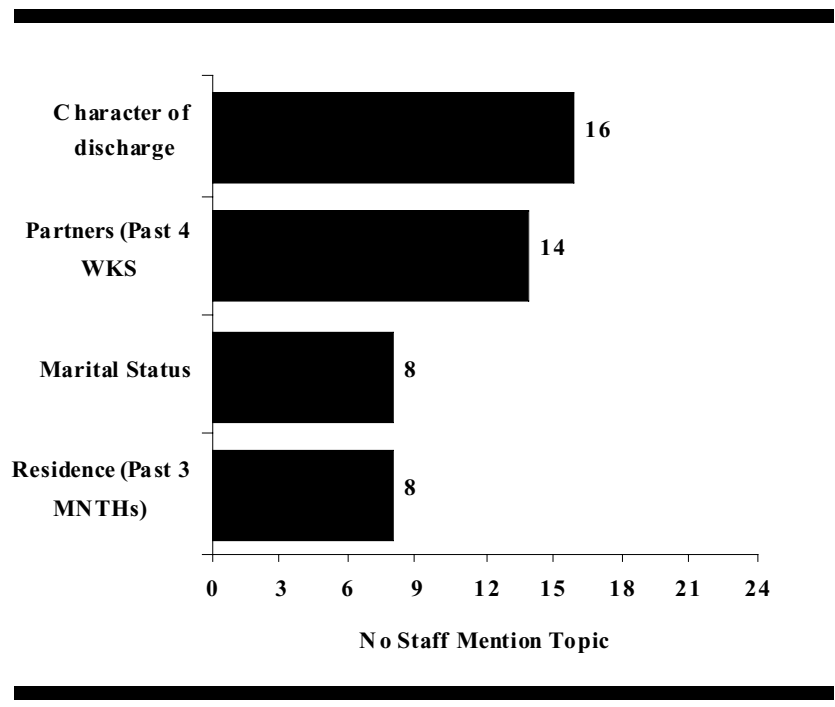

\footnotetext{
${ }^{15}$ See Wotton K.A., Ngugi E.N., and Eldridge G.,
} 

Consultations for 12 clients receiving observed. Data from these observations shov suggesting STIs are asked questions that coul STIs and HIVIAIDS. Figure 10 shows that le sexual behavior, history of STIs in their partr about STIs. Failure to ask about these issues that would have enhanced their ability to use deciding treatment for these clients. Besides, are not able to customize the client.

One of the main reasons cited by staf: their sexual behavior is that the clients do not therefore be offended by such questioning. D have an STI were asked if they perceived $t$ many of them $(59 \%)$ perceived themselves women who stated that they were at risk $(81$ sexual behavior. During the same exit intervi encounter with a new sexual partner in the $p_{c}$ asked these questions refused to answer or: These findings show that the staffs' assumptions that clients are not at risk for these diseases and may be offended by such questioning are incorrect.

Clinical examination: Apart from good risk assessment and history taking skills, the staff require good clinical examination skills to use the syndromic approach for diagnosing and treating STIs. Staff providing MC H-UP services in the NMC facilities were asked to list the procedures they would carry out during a pelvic examination for a client complaining of a vaginal discharge. A complete pelvic examination including visual inspection of the external genitalia, speculum examination and digital (bimanual) palpation of the internal genitalia is essential when assessing clients with symptoms suggesting STDs. Over two-thirds of staff interviewed said that they would carry out a speculum examination while less than half of them said that they would inspect the external genitalia and perform a digital (bimanual) examination for clients presenting with a vaginal discharge.

Data from observations of provider-client interactions for the 12 clients who received STI services general physical examination and blood pressure measurement was performed for two clients while pelvic examination was done for only one client. Although the number of observations is small, they show that clinical evaluation of clients with STIs 
is poor. Similar conclusions were made during the project's end of phase one evaluation carried out in early $\mathbf{1 9 9 5}^{\mathbf{1 6}}$. All facilities had the equipment required to measure blood pressure and weight while breast examinations do not require any equipment thus lack of equipment is not the only reason why STI clients are inadequately assessed. However, as reported earlier, many of the facilities did not have gloves, specula and antiseptic lotions on the day of the survey making it impossible for the service providers to carry out some of the required clinical examinations. Following the training the service providers were not given any reference materials or guideline to refer to while assessing clients. Lack of service manuals for reference when assessing clients may also be responsible for the inadequate clinical assessment of these clients. The algorithm charts ${ }^{17}$ provided to the clinic staff do not emphasize the clinical assessment of clients. The charts do not clearly state what examinations a service provider should carry out for clients presenting with the various syndromes.

\section{b) Clinical Assessment of family planning clients}

All the 10 new family planning and most of the 28 antenatal clients had their blood pressure and weight taken. Most of the clients also had a general physical and breast examination carried out. Pelvic examination was performed for seven of he 10 new family planning clients and only one antenatal client. For the eight pelvic examinations observed, the staff inspected the external genitalia. And carried out bimanual examination in seven procedures. Speculum examinations were undertaken for six of the observed pelvic examinations. These findings show that family planning clients are better assessed compared with clients receiving STIs despite the lack of adequate equipment and supplies. Family planning services have existed for long \ithin these facilities and there are well-designed client record forms that guide the service providers during clinical evaluation of the clients.

\section{c) Treatment of STIs}

Although the nurses have been trained in the syndromic approach, the current Ministry of Health policies do not allow then) to prescribe antibiotics. The nurses obtain the history, and carry out the clinical examination but have to refer the clients to the clinical officer or doctor for a prescription. This has limited the ability of nurses to provide a complete service to their clients. There is very little the program can do about this as it is the law in the country. According to the staff interviewed, this has undermined the confidence clients have in the nurses' ability to provide STI services. It also increases the number of staff a client has to come in contact with which compromises their privacy and increases the time taken to receive these services.

The project provides basic drugs for the treatment of STIs following the national

\footnotetext{
${ }^{16}$ See Gangopadhyay PT, Romanowski B., and Wilson D., Op. Cit.

${ }^{17}$ The National STD Unit at the Ministry of Health developed Algorithms that are distributed to all clinics in the country including the NMC Clinics
} 
guidelines. It is common to find that drug for other ailments are lacking while those for STIs are available. The staff is under strict instruction not to use STI drugs for any other ailments. This has led to frustration for staff and clients. The staff said that the scenario has also eroded the very principal of integration that the project stands for. Staff has also observed that some clients are questioning the nature and quality of drugs especially when they are free and limited to STI treatment only.

During the study, 14 clients received STO services from the facilities visited. For twelve of these clients, STD treatment was their main reason for visiting the clinics. The other two came for antenatal care but in the process were found to have symptoms suggesting STDs. Diagnosis was made using the syndromic approach for all the clients and the $\mathrm{MOH}$ algorithm was used to decide the treatment. Apart from two clients referred to the laboratory all the others were treated during the same visit.

\section{d) Provision of IEC and counseling on STIs to MCH-F'P clients}

Counseling and IEC activities are major preventative components of any STI/HIVIAIDS program. According to the model adopted by the NMC project, all clients served in their clinics would receive IEC and counseling on STIs and HIV/AIDS. This was to be carried out through group "health talks" and individual counseling at the clinics. During this case study it was found that group "health talks" are not routinely given at the clinics, and when given STIs and HIVIAIDS were not covered. During the exit interviews all clients who received MCH-FP and STI services were asked if they had been given any educational material during this visit or an earlier visit to take home from the clinic. Only five clients had ever taken educational material from the clinic and none of the materials taken covered topics on STIs and HIV/AI[)S. This was not surprising since IEC materials are generally lacking at the facilities as shown earlier in this report. STIs and HIV/AIDS are rarely discussed with MCH-FP clients during consultations. For example, STIs and HIV/AIDS were discussed in only one of the 34 and none of the ten provider-client interactions observed for the NICH and new' family planning clients, respectively.

Condom use has been shown to he effective in reducing the transmission of STI and $\mathrm{HIV}$, and staff is expected to inform all clients about this role. Only 4 of the 60 clients receiving MCH-FP services were informed about the role of condoms in reducing the rate of STI and HIV transmission. Although all clients diagnosed to have an STD should be informed about the role of condoms in the management of STDs, only two of the twelve clients treated for STDs were given any information on the value of the condom in reducing STDs and HIV transmission and none were given any condoms for use during the treatment period.

\section{e) Syphilis screening for clients receiving antenatal care}

All clients receiving antenatal care from the five NMC clinics and Provincial hospital should be screened for syphilis infection at the first antenatal clinic visit. The project has made available the necessary equipment and supplies required to carry out syphilis testing using the RPR test at the reference laboratory. In.1995, 4,577 antenatal 
the same period) were screened for syphilis as part of the project activities. Of the women screened, 31(0.7\%) tested positive for syphilis infection using the RPR test.

The treatment for syphilis is simple and inexpensive, involving a single dose therapy with Benzathine Penicillin. Untreated maternal syphilis has been associated with increased prenatal morbidity and mortality. Only 18 of the 31 women diagnosed to have syphilis infection received treatment at the clinics where they were tested. This was surprising since drugs for treating these women are provided at no cost by the project. Since these data were obtained from clinic records it was not possible to determine what happened to those women who were not treated. The small number of women receiving treatment may be because the test results are not available on the same day the specimens are taken from the clients. The RPR test is a simple procedure requiring minimal equipment, training and times to be performed. The test results can be made available soon after the specimens have been collected from a client. If these testing facilities are made available at each clinic, more women will be tested and treated without requiring them to make two or more clinic visits. This will greatly reduce the loss to follow up which is implied by the small number of women testing positive who get treated.

\section{f) Contact Tracing}

To manage STIs effectively, both partners have to be properly treated. This often calls for tracing of partners of the primary contact. Several approaches have been tried out by the NMC program which have involved counseling of the primary contact about the importance of informing and getting their partners treated. Partner notification slips have also been issued to the primary contact to give to their partners. The problem with these partner notification slips is that they bear the name of the primary contact. This compromises the privacy of the primary contact and may influence their willingness to issue their partners with the slip especially if the concerned partners are different from their spouses or regular sex partners. The study also found that only three of the clients treated for STDs were advised about partner notification.

Figure 11 shows that in 1995, 1,174 clients were treated for vaginal discharge at the five NMC clinics for the first time and contact tracing was possible for only $10 \%$ of these clients. Similarly, contact tracing was poor for clients treated for pelvic inflammatory diseases and genital ulcers. For the 31 women who tested positive for syphilis infection, contacts were traced for $36 \%$ of the cases. these data confirm that contact tracing remains a major problem for the project. The data also show that contact tracing is better for antenatal clients with syphilis infection than for non-ante-natal clients

Figure 11 Centact Tracing for Clients with STDs

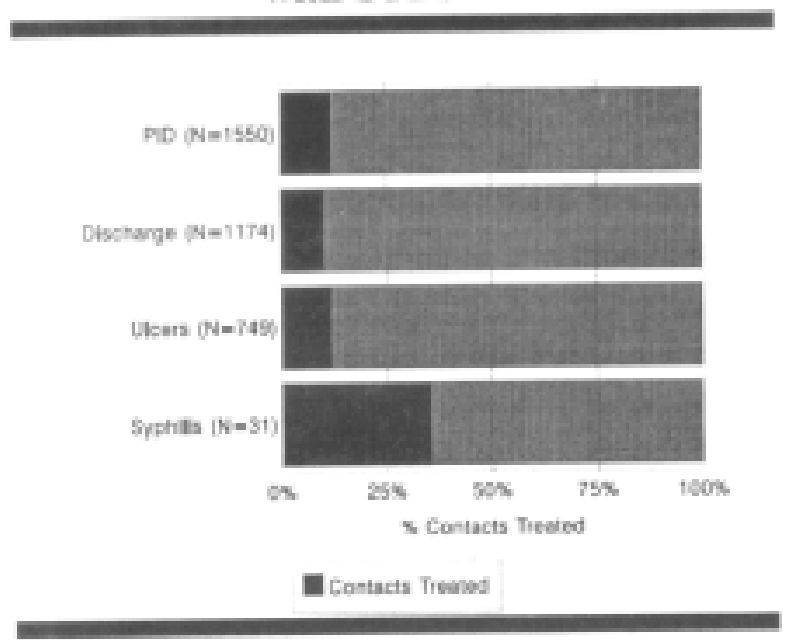




\section{Clients' Knowledge of STDs and HIV/AIDS}

The syndromic approach is entirely dependent on the ability of the service providers to obtain a good medical and social history besides a good clinical examination.

Moreover for clients to be able to present themselves to health facilities for treatment of STIs, they must know the symptoms associated with these diseases. Of the 60 clients receiving MCH-FP services, 51 (85\%) knew of diseases transmitted through sexual intercourse. These 51 clients were asked to name the common symptoms associated with STDs. Figure 12 shows that knowledge of symptoms and signs associated with STIs is poor among clients receiving MCH-FP and STI services from the

Figure 12 Knowledge of STD Symptoms Among MCH-FP Clients $(\mathbf{N}=\mathbf{5 1})$

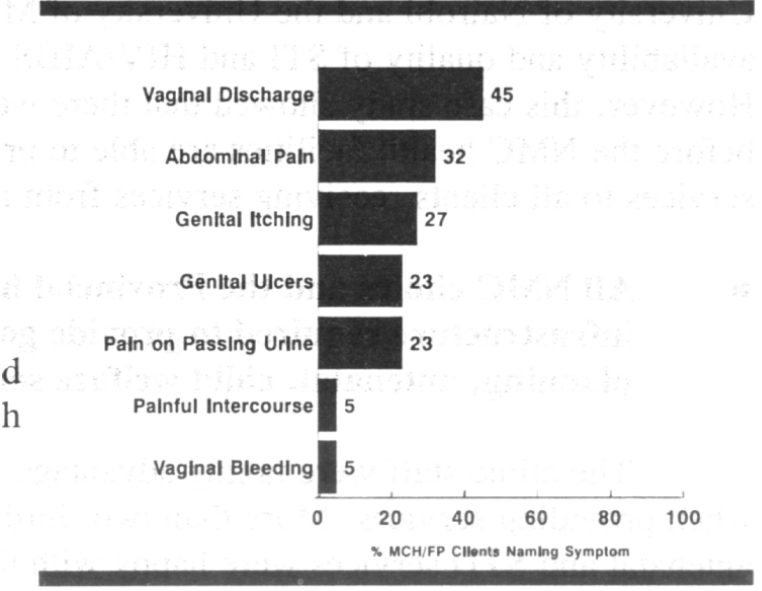
NMC health facilities.

There is no single symptom or sign that more than $50 \%$ of the clients named. The poor knowledge among these clients is not surprising given that symptoms and signs of STDs were discussed in only one of the 26 consultations (or antenatal services and none of the consultations for family planning services observed during this study.

Knowledge of symptoms associated with STDs was higher among clients who were treated for STDs. More than half the SLL) clients mentioned vaginal dischaq2e genital itching and lower abdominal pain is symptoms associated with STDS. The rest of the symptoms were mentioned by fewer than halt often clients treated for STDs (Figure 13). Symptoms and signs of STDs were discussed with clients in only two of the twelve consultations for STD services observed. These data suggest that most of these clients knew of these symptoms prior to coming to the clinic. Prior knowledge of the symptoms may have led these clients to seek STD treatment. For those clients who did not know some of the symptoms this represents a major missed opportunity to educate them about STDs.

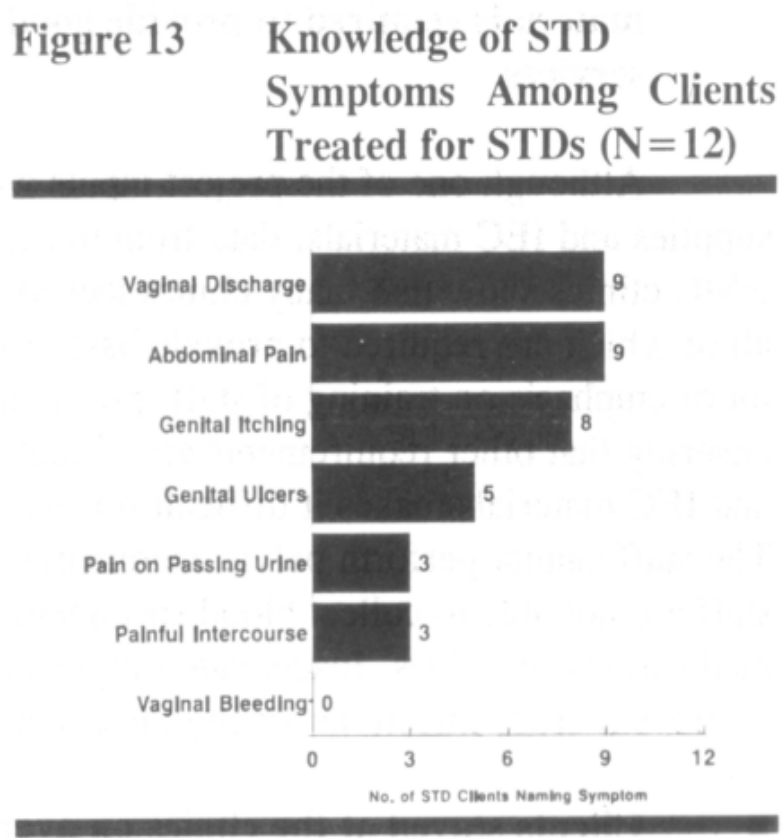

Most of the clients are not aware of other modes of $\mathrm{H1}_{-}{ }^{7}$ transmission apart from sexual intercourse. Only tour of the NICH-UP clients interviewed named "mother to baby" as a possible mode of transmission $\backslash$ 'hile none of the clients treated for STDs mentioned this 
mode of transmission. Blood transfusion was mentioned by 15 of the $60 \mathrm{MCH}$ clients and only three of the 12 clients treated for STDs.

\section{Concluding Observations}

The NMC with assistance from the Department of Community Health at the University of Nairobi and the University of Manitoba in Canada has improved on the availability and quality of STI and HIV/AIDS services within their health facilities. However, this case study showed that there were many areas that need further improvement before the NMC health facilities are able to provide high quality STI and HIV/AIDS services to all clients receiving services from these facilities.

\section{$\$$ All NMC clinics and the Provincial hospital have the basic physical infrastructure required to provide good quality STI, HIV/AIDS, family planning, antenatal, child welfare services using the integrated approach.}

The clinic staff were taking advantage of these facilities to provide privacy to client when providing services. More than two-thirds of the clients receiving family planning, antenatal and STD services were happy with the privacy accorded to them during the consultations. However, staff were not taking advantage of the waiting rooms to display IEC materials and carry out group health talks for the clients.

\& Many of the NMC clinics, the MCH-FP unit at the Provincial Hospital and the special STD clinic lacked some of the basic equipment, supplies and IEC materials required to provide good quality STD, HIV/AIDS and MCH-FP services.

Although one of the project inputs was to provide clinics with basic equipment, supplies and IEC materials, data from the case study and monthly reports prepared by the NMC clinics show that many clinics lacked gloves, antiseptic lotion needles and syringes all of which are required to provide basic STD and MCH-FP services. The project puts a lot of emphasis on training of staff, providing laboratory facilities and drugs without ensuring that other requirements are available. Lack of these essential equipment, supplies and IEC materials makes it difficult for the staff to practice what they have been trained in. The staff cannot perform pelvic examinations without gloves. Without needles and syringes staff are not able to collect blood specimens for laboratory tests and provide some of the medications for STDs. Inadequate supplies of lotion, needles and syringes make it difficult to prevent crossinfections among the clients served at these clinics.

$\$$ Clients stayed at the clinics on average for one hour and forty minutes out of which only 18-24 minutes was used for consultation with the clinic staff.

Staff often cite fears of increasing clients' waiting times as the reason for not providing group health talks or carrying out other IEC activities. However, clients are already spending a lot of time waiting for services at the clinics. This time could be utilized to provide group IEC through group talks and other audio-visual IEC activities.

\$ The availability of services is poorly advertised at all the health facilities visited. 
gone for at the health facilities. For clients to request for services, they must be aware that such services are available. Clients can be made aware through billboards, group health talks and posters all of which were generally lacking at most of the facilities visited.

$\$$ At the time of the study the majority of the staff had attended a refresher course in STD and HIV/AIDS management while fewer than half had attended any refresher courses in family planning, antenatal and child welfare services.

Many changes have taken place in the area of reproductive health since the staffs basic training and they would greatly benefit from refresher courses in all aspects of reproductive health. Although the main objective of the project is to strengthen the management of STDs and HIV/AIDS, it hopes to achieve this through the integration of STD and HIV/AIDS management with other existing services. For the successful implementation of the project, staff will have to be equipped with skills to provide all the services that are being integrated.

\section{$\$$ The refresher training provided to staff on the management of STDs and HIV/AIDS emphasize mostly the use of the syndrornic approach to diagnose and decide treatment for STDs and counseling for HIV/AIDS.}

Many female clients are usually asymptomatic and the syndromic approach is not capable of identifying them. Risk assessment and screening are essential components in the process of identifying asymptomatic clients yet these topics have not been included in many of the refresher courses attended by the staff. This is a possible explanation for the inadequate knowledge of risk factors by staff and the incomplete risk assessment carried out for clients in the project clinics. There is a need to broaden the training curriculum to include risk assessment and screening for all the refresher courses.

\section{$\$$ Nurses working in the project clinics are not allowed by Kenyan law to prescribe the medications required to treat STDs.}

Nurses at the project clinics take the history, examine and make the diagnosis for clients presenting with symptoms suggesting STDs but have to refer them to a Clinical Officer or doctor for the prescription. Clinic staff said that this practice undermines the confidence clients have in the nurses, increases the number of staff the client has to come in contact with, increases the time they have to spend at the clinics, increases staff time costs to the program and compromises clients' privacy. This is a national policy, however, and there is very little that the project can do on its own to change it.

\section{$\S$ The provision of drugs solely to treat STIs undermines the principle or integration.}

The project enabled clients with STIs to be treated using the drugs recommended by the national STD Control Program. However, at the time the NMC clinics were facing severe shortages of drugs to treat other ailments yet the staff were not expected to use the available ${ }^{1}$ STD" drugs even when the other ailments were more life threatening than the STDs. This tended to undermine the very principles of integration that staff were being trained and encouraged to adapt when providing services. The drug and other supplies situation has improved greatly since the case study. In addition to the drugs supplied by the project, the 
clinics receive drug kit containing STD and drugs for other ailments from the $\mathrm{MOH}$ funded by the Overseas Development Agency (ODA). The NMC has also introduced a cost-recovery program through funds raised from sales of the drugs and charges for services are used to purchase drugs and other supplies.

\section{\$ The algorithms to diagnose and decide treatment for STDs did not include risk assessment, screening and clinical examination as part of the process.}

Use of these algorithms may explain why staff were not carrying out STD risk assessment for $\mathrm{MCH}-\mathrm{FP}$ clients, screening and clinical examination of clients presenting with symptoms suggesting STDs. The algorithms were developed for use in STD clinics for those clients presenting with symptoms suggesting STDs. Their value in low risk populations and asymptomatic clients has Dot been clearly established. Recent studies have shown that the syndromic approach has a p\& ()V sensitivity and specificity especially when used in low risk populations. However, these can be greatly improved when risk assessment and screening are added to it. With changing expectations from the staff and populations served, there is a need to review the existing algorithms and other service provider guidelines before being adapted for use in the new situations.

\section{\$ Syphilis screening and treatment}

Many antenatal clients are getting tested for syphilis at the project clinics. However, few of the clients return for the test results and/or treatment at the clinics where they were tested. Following recommendations from the case study, the NMC has decided to decentralize syphilis testing to the clinics. Each clinic will be provided with a RPR test kit and the clinic nurses trained in the procedures required for the test. This will increase the number of antenatal clients tested and reduce the number of clients who do not return for test results and/ or treatment.

\section{\& Contact tracing and client follow up are major problem of concern to the program}

Contact tracing is achieved for fewer than half of the clients treated for the various STD syndromes at the NMC clinics. One possible explanation is that few clients informed about the importance of partner notification and treatment by the staff. 'Another explanation is that the contact tracing methods used by the program do not provide adequate privacy for the primary contact. After the case study, the NMC revised its contact follow-up slips and removed the index client's name. The contact slip now only has a number that can be used by the project to identify the clinic that issues he slip. They have also introduced a system whereby the contact does not have to get services from the same clinic as the index client but can visit any of the clinics participating in the project using he contact slip issued.

\section{$\$$ Most of the clients receiving MCH-FP services from the project clinics have poor knowledge of the symptoms, signs, complication arid modes of transmission of STDs and HIVIAIDS}

For a program that relies entirely on the syndromic approach to diagnose and treat STDs it is important that clients are knowledgeable about the symptoms associated \'ith the diseases. Clients ${ }^{1}$ knowledge remained low despite having visited the project clinics where hey are 
expected to be educated about these conditions suggesting a major missed opportunity to raise clients awareness and knowledge about STD and HIV/AIDS. Clients knowledge can be improved through group IEC activities at the clinics, individual, counseling and communitybased activities.

The study' identified several Important lessons to he learned from introducing STD and HIV/AIDS services into an existing service. The study showed that training of staff alone without addressing other issues in [he \'ork environment does not translate into high quality services. Secondly the study showed that service provider guidelines and algorithms developed for use in STD clinics may not function well in other health care settings where the prevalence of symptomatic STDs is low. Thirdly, the study showed that potential clients are not aware of the existence of STD services and have poor knowledge of the symptoms for these diseases both factors will affect the demand and use of services. Fourthly the study also showed that there are national and donor policies guidelines and practices that affect the performance of programs that cannot he solved at the program level. The NMC has to find solutions to these and other issues identified by the study. How well the identified solutions will work will be of critical importance for many, other programs in the region that are initiating or already carrying out similar approaches to service delivery in the region. 